Kong. Res. J. 4(2): 147-150, 2017

ISSN 2349-2694

Kongunadu Arts and Science College, Coimbatore.

\title{
EFFECT OF COCONUT WATER AND ACTIVATED CHARCOAL ON SEED GERMINATION IN AN ENDEMIC ORCHID RHYNCHOSTYLIS RETUSA BLUME.
}

\author{
Nisha Raj, S. \\ Department of Biotechnology, SAS SNDP Yogam College, Konni, Pathanamthitta, Kerala. \\ E.mail: nishsek@yahoo.co.in
}

\begin{abstract}
The present study on in vitro seed germination of Rhynchostylis retusa obtained on nutrient medium made clear pathway for the in vitro propagation of orchids by seed culture. The presence of coconut water in the medium enhanced seed germination and growth of seedlings. For enhancing the growth of seedlings further the individual seedlings were cultured on MS medium supplemented with $3 \mathrm{mg} / \mathrm{l} \mathrm{BAP}$ and $1 \mathrm{~g} / \mathrm{l}$ activated charcoal. These seedlings were sub cultured on rooting medium (IBA) supplemented with activated charcoal. The plantlets were transferred to soil with $90 \%$ success. Hence the present investigation made possible for the large scale multiplication of R.retusa and thus to conserve this endemic orchid.
\end{abstract}

Keywords: Rhynchostylis retusa, coconut water, activated charcoal, endemic orchid.

\section{INTRODUCTION}

In vitro culture of orchids is of much importance since the percentage germination in nature is extremely low. Conventional vegetative propagation is very slow and there are chances of virus transfer. The method help to get virus free seedlings at a faster rate. Besides, it is useful in propagating rare and endangered species and conserves them by reintroducing to the natural habitat. Essentially, the orchids are out breeders and they produce very small seeds. The seeds are produced in large numbers ranging from 1,300 to 40, 00,000 per capsule. The great majority of species have relatively undifferentiated seed, no cotyledons and no endosperms. Less than $5 \%$ of the seeds germinate in their natural environment.

Orchid embryo is a mass of undifferentiated cells, some with and others without suspensor (Manilal and Sathish Kumar, 1985). Swamy (1949) described 5 types of embryos within the group of suspensorised embryos. Two fundamental types of embryo development occur in Orchidaceae. They are: (1) Zygote divides to form an undifferentiated mass of cells from where the suspensor cells are formed earlier and filamentous proembryo. (2) Zygote divides transversally to form a linear row of four cells. The majority of orchids show the latter type of development. The sub tribes Cymbidiinae, and Crytopodiinae, where first type is seen (Vijayaraghavan, et al., 1986).

Formation of orchid seedling from the seeds involves 3 sub sequential phases namely germination, protocorm formation and seedling development (Mitra, 1976). The germination of orchid seed begun by the inhibition of water through the testa of seed. Early response of germination was noted by observing the colour and shape of the seed. First visible sign of germination is the swelling of embryo followed by their turning green and emergence of the breasted seed coats. This is called the spherical stage which subsequently develops into protocorm stage and later into the swelling stage (Mitra, 1976).

In the protocorm stage it develops rhizoids confined only to the basal region of protocorm or covers the whole except the meristamatic region. Rhizoids may be simple or branched. The formation of rhizoids in the protocorm is a unique feature of Orchidaceae. Subsequent cell divisions occur both in the apical and basal regions of the protocorm and leaf primordia, morphogenesis is started from the shoot meristem. Later first roots are formed endogenously (Mitra, 1971).

The in vitro culture of orchid seeds reveals that the seeds obtained from green pod 8-12 weeks of anthesis, germinate readily in a large number of species. The mature seeds on the other hands are hard to germinate due to some dormancy factors (Mitra, 1976).

Of the various media tried for seed germination the one formulated by Burgeff (1936), Knudson (1946), Vacin and Went (1940), Raghavan and Torrey (1964) and (Mitra et al., 1976) with lesser amounts of ammonium, nitrates, calcium, potassium and phosphate ions along with several vitamins have been found to be most suitable for a large number of orchids. The additional presence of amino acids, urea, casein hydrolysate, yeast extract, 
coconut milk, auxins, cytokinins, adenine and gibberellins in the medium has yielded a better germination of embryos and protocorm formation. (Swamy, 1949). Vitamins also play an important role in the germination and in maintaining the development of germinating seeds (Anderson 1967; Arditi 1967). Apart from seed germination and meristem culture, other parts of plants viz. leaves, leaf tip and inflorescence are also used as explants.

Plant tissue culture offers several advantages over conventional propagation vegetative and sexual methods, for large scale propagations. Shoot multiplication can be achieved in small space because miniature plantlets are produced

\section{MATERIALS AND METHODS}

\subsection{Culture media}

Murashige and Skoog's (1962) 1/2 strength basal media was used for the present in vitro studies of Rhyncostylis retusa. Half strength of medium (Table 1) with coconut water were used for the germination of $R$. retusa seeds.

\subsection{Preparation of the media}

Chemicals of high purity were used for the media preparation. The stock solutions of macro and micro elements were prepared separately and stored in glass bottles under refrigeration at 5o-10oC. All the stock solutions for MS media were prepared and stored separately. Appropriate quantities of the various stock solutions (Here half strength MS medium used), growth regulators and other supplements were mixed and the final volume of the medium was made up with double distilled water.

$\mathrm{pH}$ of the media were adjusted to 5.8 after adding plant growth regulators and coconut milk using $0.1 \mathrm{~N}$. $\mathrm{NaOH}$ and $0.1 \mathrm{~N} \mathrm{HCl}$. Medium was solidified by adding agar. About $15 \mathrm{ml}$ of the medium is dispensed to each culture tube and sterilized in an autoclave at $15 \mathrm{lbs}$, for 20 minutes. Half strength MS Medium with 20\% coconut water was added.

For rooting of the germinating seedlings $1 / 2$ MS medium supplemented with IBA (1-3 mg) were employed. The media were also supplemented with 0.5-3 gm/l of activated charcoal. Activated charcoal added along with IBA enhanced.

\subsection{Preparation of the explant and inoculation}

The green immature undehised capsules of Rhyncostylis retusa were collected from the field. The capsules were washed in tap water and brought to the inoculation chamber. The capsules were soaked in rectified sprit and surface burned. They were then opened longitudinally with a sterile blade. Seeds were immediately transferred to MS medium under aseptic conditions. The cultures were incubated at $25 \pm 2^{\circ} \mathrm{C}$ temperature conditions.

The percentage of germination and frequency of plant emergence were recorded initially from 45 days and then continue every 15 days interval from the day of inoculation. The changes were observed, studied and recorded with the help of a dissection microscope.

\subsection{Germination rooting and transfer of the plant}

Immature sterile seeds were cultured on MS media supplemented with coconut water (10 - 20\%). Cultures were observed initially after 45 days and then continue observation at every 15 days interval. Germination begins from 45 days of culture and on 120 th day of inoculation full plantlets developed. After 120 days of culture the plantlets were isolated and cultured on MS media supplemented with BAP at 3 different concentrations (1, 2, $3 \mathrm{mg} / \mathrm{l})$ and three different concentrations of activated charcoal $(1,2,3$ $\mathrm{gm} / \mathrm{l})$.

After four weeks the plantlets attained a length of about 3 to $4 \mathrm{~cm}$ with 2 to 3 leaves each. These seedlings were sub cultured on to MS medium containing four different concentration of IBA (1, 2, 3 and $4 \mathrm{mg} / \mathrm{l}$ ) supplemented with four different concentration of activated charcoal $(0.5,1,2$ and 3 $\mathrm{gm} / \mathrm{l})$.

After six weeks, plantlets with well developed roots were transferred to soil and grown under green house conditions. The rooted plantlets were thoroughly washed in distilled water to remove the agar and transferred to garden soil mixed with wood charcoal (1:1) in plastic cups ( under diameter $6 \mathrm{~cm} \times$ length $8 \mathrm{~cm}$ ) and placed in a glass house under high humidity (90\%). The plantlets were kept under sterile conditions in plastic containers for 2 months after which they were transplanted to field.

\section{RESULTS AND DISCUSSION}

The present investigation was carried out with the objective of rapid multiplication through in vitro seed germination of Rhynchostylis retusa, an endemic wild and rare orchid.

The seeds from the fruits collected from the field were cultured on MS medium supplemented with various concentrations of coconut milk after sterilization. The various events occurred during the germination period of the seed were studied with a dissection microscope and is shown in the Table II. The initial sign of seed germination was observed 
after 45 days of culture. Within 120 days the seeds were germinated up to a length of $1 \mathrm{~cm}$ (Fig. $1 \mathrm{~A}$ and 1B).

The effect of various concentrations of coconut milk on seed germination was studied. The earlier reports suggest that coconut milk plays a very crucial role in seed germination of orchid (Hegarty, 1955; Nimoto and Sagawa, 1961; Cheng and Chua, 1980; Mitra, 1976). An optimum concentration of $15 \%$ coconut milk gave maximum response after 120 days of culture (Table III). Hence it was confirmed that coconut milk enhances the seed germination in $R$. retusa.

After 120 days of culture the seedlings were about $1 \mathrm{~cm}$ in length without roots. For enhancing the growth of the seedlings, the individual seedlings were culture on MS medium supplemented with different concentrations of BAP $(1,2,3$ and $4 \mathrm{mg} / \mathrm{l})$ and activated charcoal (1-3 gm/l), $3 \mathrm{mg} / \mathrm{l}$ BAP and 1 $\mathrm{gm} / \mathrm{l}$ activated charcoal gave optimum results. On this medium seedlings reached an average height of about 2.8cm (Fig. 2A and 2B; Fig. 3A and 3B).

Table 2. Various changes observed during the seed culture in $R$. retusa on three different concentrations of coconut milk.

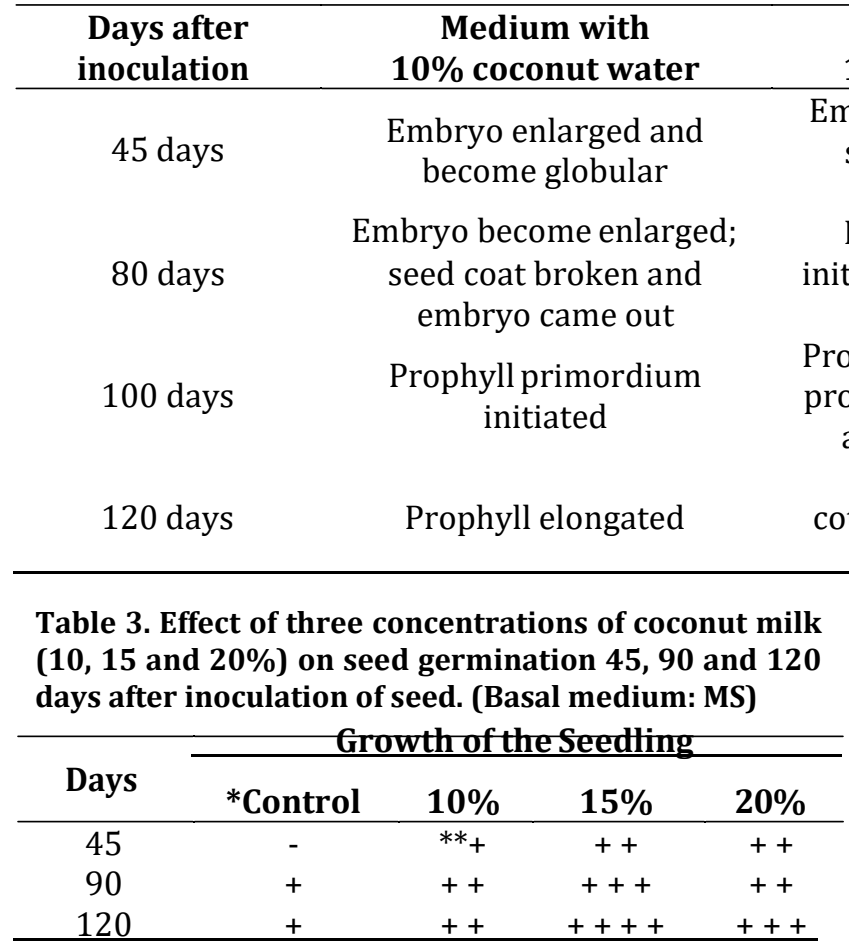

* Medium without coconut milk; ** The progressive ' + ' signs

indicate an increase in pace of seed growth.

Table 4. Effect of different concentrations of IBA (1-4 mg/l) and activated charcoal $(0.5-3 \mathrm{~g} / \mathrm{l})$ on root induction from the germinated shoots of $R$. retusa. Observations were taken after 45 days of culture.

\begin{tabular}{ccccc}
\hline $\begin{array}{c}\text { 1/2 MS IBA } \\
\mathbf{m g} / \mathbf{l}\end{array}$ & $\begin{array}{c}\text { Charcoal } \\
\text { gm/l }\end{array}$ & $\begin{array}{c}\text { \% } \\
\text { rooting }\end{array}$ & $\begin{array}{c}\text { Average } \\
\text { number of } \\
\text { roots }\end{array}$ & $\begin{array}{c}\text { Average } \\
\text { length of } \\
\text { roots } \\
\text { (cm) }\end{array}$ \\
\hline${ }^{*}$ Control & 0 & - & - & - \\
1 & 0.5 & 55 & 1 & 1.0 \\
2 & 1 & 72 & 3 & 1.1 \\
3 & 2 & 98 & 3.8 & 1.7 \\
4 & 3 & 78 & 3.2 & 1.4 \\
\hline
\end{tabular}

* Control: $1 / 2$ MS basal medium

The root development was very poor with the seedlings. Later, for further growth of seedlings, the seedlings were sub cultured on half MS supplemented with different concentrations of IBA (1 to $4 \mathrm{mg} / \mathrm{l}$ ) and activated charcoal. Maximum response was observed on MS+IBA (3 mg/l) and

activated charcoal ( $2 \mathrm{mg} / \mathrm{l}$ ) on the medium $98 \%$ of the shoots rooted with an average number of 3.8 roots per shoot (Table IV) (Fig. 4A and 4B).

Plantlets were transferred to soil with $90 \%$ success (Fig. 5A and 5B). The rooted plantlets were thoroughly washed in distilled water and transferred to plastic cups containing garden soil mixed with charcoal. They were placed in a glass house under high humidity. After two months the plantlets were transferred to the field. The procedure developed here is helpful in rapid multiplication of R.retusa and thus to conserve this rare orchid.

Several investigators employed immature seeds from unripe green pods for in vitro germination experiments especially in orchids like Cymbidium, Dendrobium, Epidendum, Oncidium, Vanda etc. Normally the fertilized ovules were collected 8 to 16 weeks after pollination were used for in vitro seed germination on a suitable medium. The difficulty with these experiments is that identifying the critical stage of immature seeds before they pass on to the dormant stage. As the mature and immature seeds can be hardly distinguished morphologically, some biochemical experiments are needed for identifying the right type of immature seeds. Raghavan (1976) described the changes in enzyme compliments as the orchid seed changes from immature to mature stage.

The culture of ovules or seeds from fruits can be extended to study in vitro pollination and fertilization leading to hybrid production. The propagation of orchid via. seed germination include three stages ie. germination, protocorm formation and seedling development. The development of a germinated seed via. protocorm into seedlings may be called as "direct" method. In other cases the embryos may form spontaneous callus formation during germination (Curtis and Nichols, 1948; Withner, 1959; Goh, 1970; Mitra et.al., 1976; Vij 
et.al., 1981). Here the multiplication pathway is via. organogenesis and it depend upon medium and plant growth regulators. Hence the seed callus via. Protocorm formation developing into seedling can be referred to as "indirect" method. This is basically used for obtaining hybrid orchids from embryos.

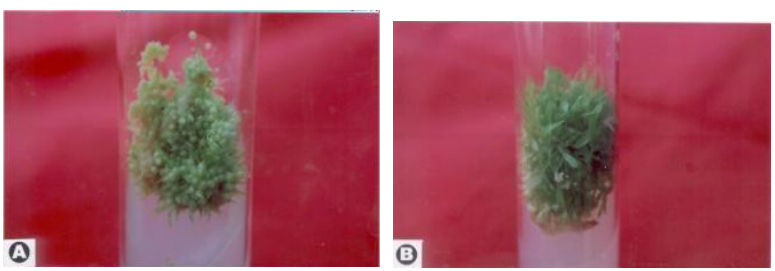

Fig. 1(A): An 80 days old seed culture of $R$. retusa on MS medium supplemented with $15 \%$ coconut water. The seeds have started germinating and produced prophyll primordium. (B): A 100 days old seed culture on MS $+15 \%$ coconut milk. The prophylls have elongated and each plantlets can be distinguished.

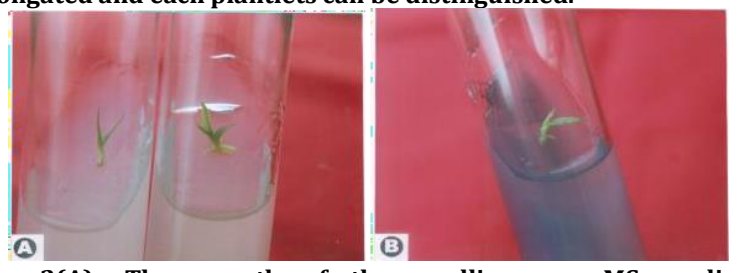

Fig. 2(A): The growth of the seedlings on MS medium supplemented with BAP $\mathrm{mg} / \mathrm{l}$ without activated charcoal. (B): An isolated seedling on MS medium supplemented with BAP $(3 \mathrm{mg} / \mathrm{l}$ + activated charcoal $1 \mathrm{gm} / \mathrm{l}$ ) for further growth, one week after inoculation. Comparatively the presence of activated charcoal on the media enhances the growth of the seedlings.

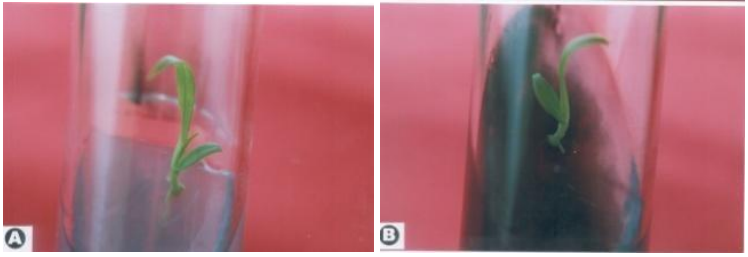

Fig. 3(A): A 45 days old seedling on MS medium supplemented with BAP $3 \mathrm{mg} / \mathrm{l}+$ activated charcoal $1 \mathrm{gm} / \mathrm{l}$. The seedlings have reached a size of about $2.5 \mathrm{~cm}$ length and rudimentary roots have developed at the base. (B): Seedling on MS medium supplemented with BAP $3 \mathrm{mg} / \mathrm{l}+$ activated charcoal $3 \mathrm{~g} / \mathrm{l}$ for germination. The growth was poor as compared to $1 \mathrm{gm} / \mathrm{l}$ activated charcoal.

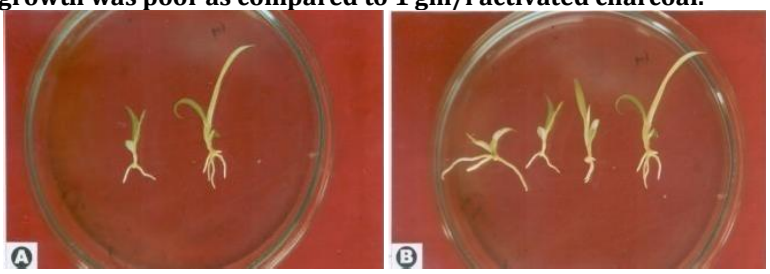

Fig. 4(A): Induction of roots on $1 / 2$ MS medium supplemented with IBA $3 \mathrm{mg} / \mathrm{l}$ and activated charcoal $2 \mathrm{~g} / \mathrm{l}$. Well developed healthy roots have developed from the seedling. (B): Four seedlings showing the various stages of root development on $1 / 2$ MS medium supplemented with IBA $3 \mathrm{mg} / \mathrm{l}$ and activated charcoal $2 \mathrm{~g} / \mathrm{l}$ after 45 days of sub culture. The roots have reached an average length of $1.7 \mathrm{~cm}$.

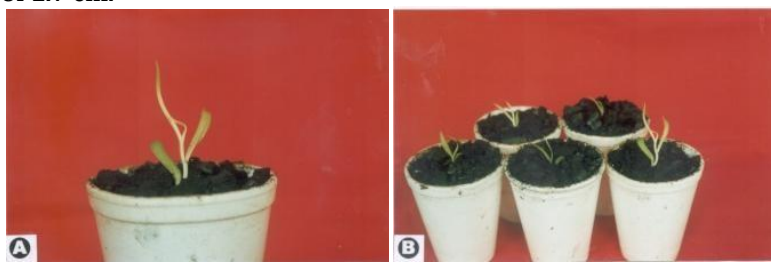

Fig. 5(A): A hardened plant one week after transfer to soil and wood charcoal. (B): Five plantlets transferred to soil growing at various stages of development 2 week after transfer.

\section{REFERENCES}

Anderson, l. (1967). Literature review of orchid seed germination. Am. Orchid Soc. Bull., 36: 304 - 308.

Arditti, J. (1967). Factors affecting the germination of orchid seed. Bot. Rev. 33: 1 - 97.

Arditti, J. (1968). Germination and growth orchid seeds on banana fruit tissue and some of its extracts. Am. Orchids Soc. Bull., 37: $112-116$.

Burgeff, H. (1936). Die Samen Kiemung Der Orchideen, G.Fischer, Jena.

Chemg, Y.W. and S.E. Chua. (1980). Mass propagation of orchid plants from orchid seeds using the airflow system to accelerate growth. Singapore J. Prim. Ind., 8: 57-62.

Clement, M.A. (1973). The non-symbiotic and symbiotic germination of orchid seeds. Orchid Rev. 81: 152 - 154.

Curtis, J. T. and N.A. Nichols. (1948). Culture of proliferating orchid embryo in vitro. Bull. Torry Bot. Club, 75: 358 - 77.

Gamble, J.S. (1928). Flora of presidency of Madras. Vol. 3. Aldlard and Sons, London.

GOH, C.J. 1970. Some effects of auxin on orchid seed germination and seedling growth. Mal. Orchid Rev., 9: 115118.

Hegarty, c.p. (1955). Observations of germination of orchid seed. Am. Orchid Soc. Bull. 23: 78 - 81.

Jain, S.K. and A. Malhotra. (1984). A preliminary inventory of Orchidaceae. India. BSL Howrah.

Kundson, L. (1922). Non-symbotic germination of orchid seed. Bot. Gaz. 73: 1- 25.

Kundson, L. (1951). Nutrient solutions for orchids, Bot. Gaz., 112: $528-532$.

Kumar, M., and Sasidharan. (1985). Orchids of Kerala and there conservation, In S.P. Vij. (Ed.), Biology, conservation and culture of orchids, Affiliated to East-West Press, New Delhi.

Mitra, G.C., (1971). Studies on seeds shoot tips and discs of an orchid grown in aseptic culture. Indian J. exp. Biol. 9: 79 85.

Mitra, G.C.; R.N. Prasad and A. Roy Chowdhury, (1976). Inorganic salts and differentiation of protocorm in seed callus of an orchid and correlated changes in its free amino acid content, Indian, J. exp. Biol., 14: 350 - 351.

Nimoto, D. H and Y. Sagawa. (1961). Ovule development in Dendroblum. Am. Orchid Soc. Bull., 30:813-19.

Raghavan, V. and J. G. Torrey. (1964). Inorganic nitrogen nutrition of the embryos of the orchid, Cattleya, Arm. J. Bot., 51:264274.

Raghavan, V. (1976). Experimental Embryogenesis in Vascular Plants. Academic Press, London.

Swamy. (1949). Embryological studies in the Orchidaceae / Gametophytes.

Vacin, E. and F.W. Went. (1949). Some changes in the nutrient solutions, Botan. Gaz., 110:605-613.

Vijayaraghavan, M.R.,(1986). Reproductive study in orchids: Ultra structural and cytochemical appraisal. In S.P. VIJ (Ed.) Biology, conservation and Culture of Orchids. Affilated EastWest Press, New Delhi.

Vij, S.P., A. Sood and K.K. Plaha, (1981). Invitro seed germination of some epiphytic orchids. In Contemporary Trends in Plant Sciences (ed. S.C. VERMA). Kalyani publishers, New Delhi.

Withner, C.L. (1959). The orchids: A scientific survey. Ronald Press, New Delhi. 